\title{
Association of increased CCL5 and CXCL7 chemokine expression with neutrophil activation in severe stable COPD
}

\author{
A Di Stefano, ${ }^{1}$ G Caramori, ${ }^{2}$ I Gnemmi, ${ }^{1}$ M Contoli, ${ }^{2}$ L Bristot ${ }^{2}$ A Capelli, ${ }^{1}$ \\ F L M Ricciardolo, ${ }^{3}$ F Magno, ${ }^{1}$ S Ennio D'Anna, ${ }^{4}$ A Zanini, ${ }^{1}$ M Carbone, ${ }^{1} \mathrm{~F}$ Sabatini, ${ }^{5}$ \\ C Usai, ${ }^{6}$ P Brun, ${ }^{7}$ K F Chung, ${ }^{8}$ P J Barnes, ${ }^{8}$ A Papi, ${ }^{2}$ I M Adcock, ${ }^{8}$ B Balbi ${ }^{1}$
}

- Additional details are published online only at http:// thorax.bmi.com/content/vol64/ issue11

${ }^{1}$ Division of Pulmonary Disease and Laboratory of

Cytoimmunopathology of Heart and Lung, Salvatore Mauger

Foundation, IRCCS, Veruno, Italy;

${ }^{2}$ Centro di Ricerca su Asma e BPCO, Università di Ferrara, Italy; ${ }^{3}$ Department of Pulmonary Disease, University of Torino, Italy; ${ }^{4}$ Divisione di Pneumologia, Fondazione San Raffaele, IRCCS G Giglio, Cefalù, Italy; ${ }^{5}$ Unit of Respiratory Disease, IRCCS Gaslini Institute, Genoa, Italy;

${ }^{6}$ Istituto di Cibernetica e

Biofisica, CNR, Genoa, Italy;

${ }^{7}$ Department of Histology,

Microbiology and Medical

Biotechnology, University of

Padova, Italy: ${ }^{8}$ Airways Disease

Section, National Heart and

Lung Institute, Imperial College

London, UK

Correspondence to:

Dr A Di Stefano, Fondazione S

Maugeri, IRCCS, Laboratorio di

Citoimmunopatologia Apparato

Cardio Respiratorio, Via per

Revislate 13, 28010 Veruno

(NO), Italy; antonino.distefano@

fsm.it

$\mathrm{ADS}$ and GC contributed equally to this work.

Received 12 January 2009

Accepted 22 July 2009

Published Online First

23 August 2009

\section{ABSTRACT}

Background: Increased numbers of activated neutrophils have been reported in the bronchial mucosa of patients with stable chronic obstructive pulmonary disease (COPD), particularly in severe disease.

Objectives: To investigate the expression of neutrophilic chemokines and adhesion molecules in bronchial biopsies from patients with stable COPD of different severity (GOLD stages I-IV) compared with age-matched control subjects, smokers with normal lung function and never smokers.

Methods: The expression of CCL5, CXCL1, 5, 6, 7 and 8, CXCR1, CXCR2, CD11b and CD44 was measured in the bronchial mucosa using immunohistochemistry, confocal immunofluorescence, real-time quantitative polymerase chain reaction (RT-OPCR) and Western blotting (WB).

Results: The numbers of CCL5+ epithelial cells and CCL5+ and CXCL7+ immunostained cells were increased in the bronchial submucosa of patients with stable severe COPD compared with control never smokers and smokers with normal lung function. This was also confirmed at the level of mRNA expression. The numbers of CCL5+ cells in the submucosa of patients with COPD were 2-15 times higher than any other chemokines. There was no correlation between the number of these cells and the number of neutrophils in the bronchial submucosa. Compared with control smokers, the percentage of neutrophils coexpressing CD11b and CD44 receptors was significantly increased in the submucosa of patients with COPD.

Conclusion: The increased expression of CCL5 and CXCL7 in the bronchial mucosa of patients with stable COPD, together with an increased expression of extracellular matrix-binding receptors on neutrophils, may be involved in the pathogenesis of COPD.

Inflammation occurs in the central peripheral airways (bronchioles) and lung parenchyma of patients with COPD. ${ }^{1-4}$ Studies have emphasised the potential pathological role of many inflammatory cells including macrophages and $\mathrm{T}$ lymphocytes, whereas fewer investigations have examined neutrophil granulocytes despite increased numbers being present in the bronchial mucosa, particularly in severe disease. ${ }^{4-9}$ Furthermore, the need for more pathological investigations in patients with severe COPD has been highlighted. ${ }^{3}$

Several chemokines of the CXC and CC family are involved in neutrophil chemotaxis. ${ }^{10-35} \mathrm{CXC}$ chemokines were principally investigated using bronchoalveolar lavage (BAL) fluid or sputum samples, and increased levels of $\mathrm{CXCL}^{12}$ and
CXCL8 $^{21}$ in sputum or CXCL5 in BAL fluid ${ }^{14}$ have been reported in patients with COPD.

Fewer studies have investigated the expression of CC chemokines in COPD. CCL5 levels are increased in the sputum of patients with COPD. ${ }^{23}$ The leukocyte $\alpha_{M} \beta_{2}$ integrin (also known as CD11b/ CD18) functions as an adhesion molecule facilitating diapedesis. Overexpression of CD11b has been reported in peripheral blood neutrophils ${ }^{26}{ }^{27}$ and sputum $^{28}$ of patients with COPD. Finally, hyaluronan, an extracellular matrix component, is the main ligand for CD44 and its expression is upregulated in neutrophils co-cultured with human primary bronchial epithelial cells and granulocytemacrophage colony stimulating factor (GM-CSF). ${ }^{31}$ The expression of CD11b and CD44 on neutrophils in the bronchial mucosa of patients with COPD has not been previously reported (see online data supplement for a more detailed background).

The mechanisms responsible for tissue neutrophilia in COPD have not been fully clarified. The prevalence of neutrophils can be related to increased chemotaxis, increased adhesion to collagens or to prolonged survival. A partial loss of neutrophilic chemotactic response to CXCL8 stimuli has recently been reported for sputum neutrophils in patients with COPD after migration and residence in the bronchial lumen. ${ }^{10}$ Furthermore, a comprehensive analysis of chemokine expression in COPD bronchi is lacking.

The aim of the present study was to investigate the presence of relevant CXC and CC chemokines, cytokines and chemokine receptors involved in neutrophilic migration and activation in bronchial biopsies from patients with increasing disease severity. Since increased adhesion of neutrophils to extracellular matrix components may play a role in neutrophil permanence in the bronchial mucosa, the expression of two neutrophil receptors, CD11b and CD44, potentially involved in this process was also studied.

\section{METHODS}

\section{Subjects}

All subjects were recruited from the Section of Respiratory Medicine of the Fondazione Salvatore Maugeri (Veruno, Italy). Table 1 and Tables E1-E3 (in the online data supplement) show the clinical characteristics of the subjects used for the immunohistochemistry ( $n=49)$, confocal microscopy $(n=8)$, real-time PCR (RT-PCR, $\mathrm{n}=31$ ) and Western blotting $(n=12)$ studies. The severity of the airflow obstruction was staged according to the GOLD criteria. 
Table 1 Characteristics of subjects for the optical immunohistochemical study

\begin{tabular}{|c|c|c|c|c|c|c|c|c|}
\hline Subjects & n & Age (years) & $\mathrm{M} / \mathrm{F}$ & $\begin{array}{l}\text { Smoking history } \\
\text { (pack-years) }\end{array}$ & $\begin{array}{l}\text { Ex/current- } \\
\text { smokers }\end{array}$ & $\begin{array}{l}\text { FEV } 1 \text { pre } \\
\text { (\% pred) }\end{array}$ & $\begin{array}{l}\text { FEV }{ }_{1} \text { post } \\
\text { (\% pred) }\end{array}$ & $\mathrm{FEV}_{1} / \mathrm{FVC} \%$ \\
\hline Healthy non-smokers & 11 & $62(4)$ & $12 / 1$ & 0 & 0 & $115(4)$ & ND & $85(3)$ \\
\hline Healthy smokers & 13 & $60(2)$ & $9 / 3$ & $46(12)$ & $2 / 11$ & $107(4)$ & ND & $82(2)$ \\
\hline Severe/very severe COPD & 13 & $65(3)$ & $4 / 7$ & $49(11)$ & $9 / 4$ & $30(2)^{*} \dagger$ & $33(3)$ & $42(3)^{*} \dagger$ \\
\hline
\end{tabular}

Data are presented as mean (SEM).

COPD, chronic obstructive pulmonary disease; F, female; FEV ${ }_{1}$, forced expiratory volume in $1 \mathrm{~s}$; FVC, forced vital capacity; M, male; ND, not determined.

${ }^{*} p<0.001$ (ANOVA) significantly different from control smokers with normal lung function (healthy smokers) and control never-smokers.

$+\mathrm{p}<0.001$ (ANOVA) significantly different from mild/moderate COPD.

fFor patients with COPD, $\mathrm{FEV}_{1} / \mathrm{FVC} \%$ are post-bronchodilator values.

The GOLD classification of severity for COPD has been followed where patients are classified as mild (GOLD stage I), moderate (stage II), severe (stage III) and very severe (stage IV).

\section{Lung function tests and volumes}

Pulmonary function tests were performed as previously described $^{6}$ according to published guidelines (see online data supplement).

\section{Fibreoptic bronchoscopy, collection and processing of bronchial biopsies}

A standardised procedure, previously reported, ${ }^{6}$ was followed for fibreoptic bronchoscopy and collection of bronchial biopsies. Bronchial biopsies for immunohistochemistry, Western blot analysis and RT-OPCR were processed as previously described ${ }^{6}$ (see online data supplement for details).

\section{Immunohistochemistry}

A panel of antibodies was used (table 2) and primary antibodies were applied at optimal dilutions in TRIS-buffered saline and revealed with the use of appropriate secondary antibodies and fast-red substrate (see online data supplement for details).

\section{Immunofluorescence staining with confocal microscopy}

Sections were fixed with $4 \%$ paraformaldehyde, washed with phosphate buffered saline (PBS) and incubated with blocking serums followed by incubation with primary antibodies and the revealing antibody system, as previously described ${ }^{32}$ (see online data supplement for details).

Scoring system for immunohistochemistry and confocal microscopy Light microscopic analysis was performed at a magnification of $630 \times$. Immunostained cells in the bronchial submucosa were quantified as previously described. ${ }^{6}$ The immunostaining was also scored in the bronchial epithelium. The quantitative estimation of co-localised proteins was performed calculating

Table 2 Antibodies used to characterise inflammatory cells and CXC, CC chemokines, their receptors and other molecules involved in the neutrophilia of the bronchial mucosa

\begin{tabular}{|c|c|c|c|c|c|c|c|}
\hline $\begin{array}{l}\text { Antibody } \\
\text { specificity }\end{array}$ & Company & Catalogue number & Source/host & $\begin{array}{l}\text { Dilution of the } \\
\text { primary antibody }\end{array}$ & $\begin{array}{l}\text { Biotinylated } \\
\text { secondary } \\
\text { antibody }\end{array}$ & Revealing kit & Positive control \\
\hline CXCL1 & R\&D Systems & AF-275 & Goat & $1: 50$ & $\begin{array}{l}\text { Vector, BA 5000; } \\
1: 200\end{array}$ & $\begin{array}{l}\text { Dako, } \\
\text { StreptABComplex/ } \\
\text { AP; } 1: 100\end{array}$ & Nasal polyp \\
\hline CXCL5 & R\&D Systems & MAB-254 & Mouse & $1: 50$ & $\begin{array}{l}\text { Vector, BA 2000; } \\
1: 200\end{array}$ & $\begin{array}{l}\text { Dako, } \\
\text { StreptABComplex/ } \\
\text { AP; } 1: 100\end{array}$ & Nasal polyp \\
\hline CXCL6 & Santa Cruz & SC-5813 & Goat & $1: 50$ & $\begin{array}{l}\text { Vector, BA 5000; } \\
1: 200\end{array}$ & $\begin{array}{l}\text { Dako, } \\
\text { StreptABComplex/ } \\
\text { AP; } 1: 100\end{array}$ & Nasal polyp \\
\hline CXCL7 & R\&D Systems & MAB393 & Mouse & $1: 50$ & $\begin{array}{l}\text { Vector, BA 2000; } \\
1: 200\end{array}$ & $\begin{array}{l}\text { Dako, } \\
\text { StreptABComplex/ } \\
\text { AP; } 1: 100\end{array}$ & Nasal polyp \\
\hline CXCL8 & R\&D Systems & AF-208NA & Goat & $1: 50$ & $\begin{array}{l}\text { Vector, BA 5000; } \\
1: 200\end{array}$ & $\begin{array}{l}\text { Dako, } \\
\text { StreptABComplex/ } \\
\text { AP; } 1: 100\end{array}$ & Nasal polyp \\
\hline CCL5 & R\&D Systems & AF-278NA & Goat & $1: 100$ & $\begin{array}{l}\text { Vector, BA 5000; } \\
1: 200\end{array}$ & $\begin{array}{l}\text { Dako, } \\
\text { StreptABComplex/ } \\
\text { AP; } 1: 100\end{array}$ & Nasal polyp \\
\hline CXCR1 & R\&D Systems & MAB330 & Mouse & $1: 200$ & $\begin{array}{l}\text { Vector, BA 2000; } \\
1: 200\end{array}$ & $\begin{array}{l}\text { Dako, } \\
\text { StreptABComplex/ } \\
\text { AP; } 1: 100\end{array}$ & Nasal polyp \\
\hline CXCR2 & R\&D Systems & MAB331 & Mouse & $1: 200$ & $\begin{array}{l}\text { Vector, BA 2000; } \\
1: 200\end{array}$ & $\begin{array}{l}\text { Dako, } \\
\text { StreptABComplex/ } \\
\text { AP; } 1: 100\end{array}$ & Nasal polyp \\
\hline $\mathrm{CD} 44$ & AMS-Biotech & 211-JM144A & Mouse & $1: 100$ & $\begin{array}{l}\text { Vector, BA 2000; } \\
1: 200\end{array}$ & $\begin{array}{l}\text { Dako, } \\
\text { StreptABComplex/ } \\
\text { AP; } 1: 100\end{array}$ & Nasal polyp \\
\hline CD11b & R\&D Systems & MAB16991 & Mouse & $1: 50$ & $\begin{array}{l}\text { Vector, BA 2000; } \\
1: 200\end{array}$ & $\begin{array}{l}\text { Dako, } \\
\text { StreptABComplex/ } \\
\text { AP; } 1: 100\end{array}$ & Nasal polyp \\
\hline $\begin{array}{l}\text { Neutrophil } \\
\text { elastase }\end{array}$ & Dako & M752 & Mouse & $1: 100$ & $\begin{array}{l}\text { Vector, BA 2000; } \\
1: 200\end{array}$ & $\begin{array}{l}\text { Dako, } \\
\text { StreptABComplex/ } \\
\text { AP; } 1: 100\end{array}$ & Human tonsil \\
\hline
\end{tabular}


Table 3 Quantification of inflammatory cells and chemokines and their receptors in the bronchial epithelium and submucosa of patients with COPD stratified by GOLD stage of severity, control smokers with normal lung function and control non-smoking subjects

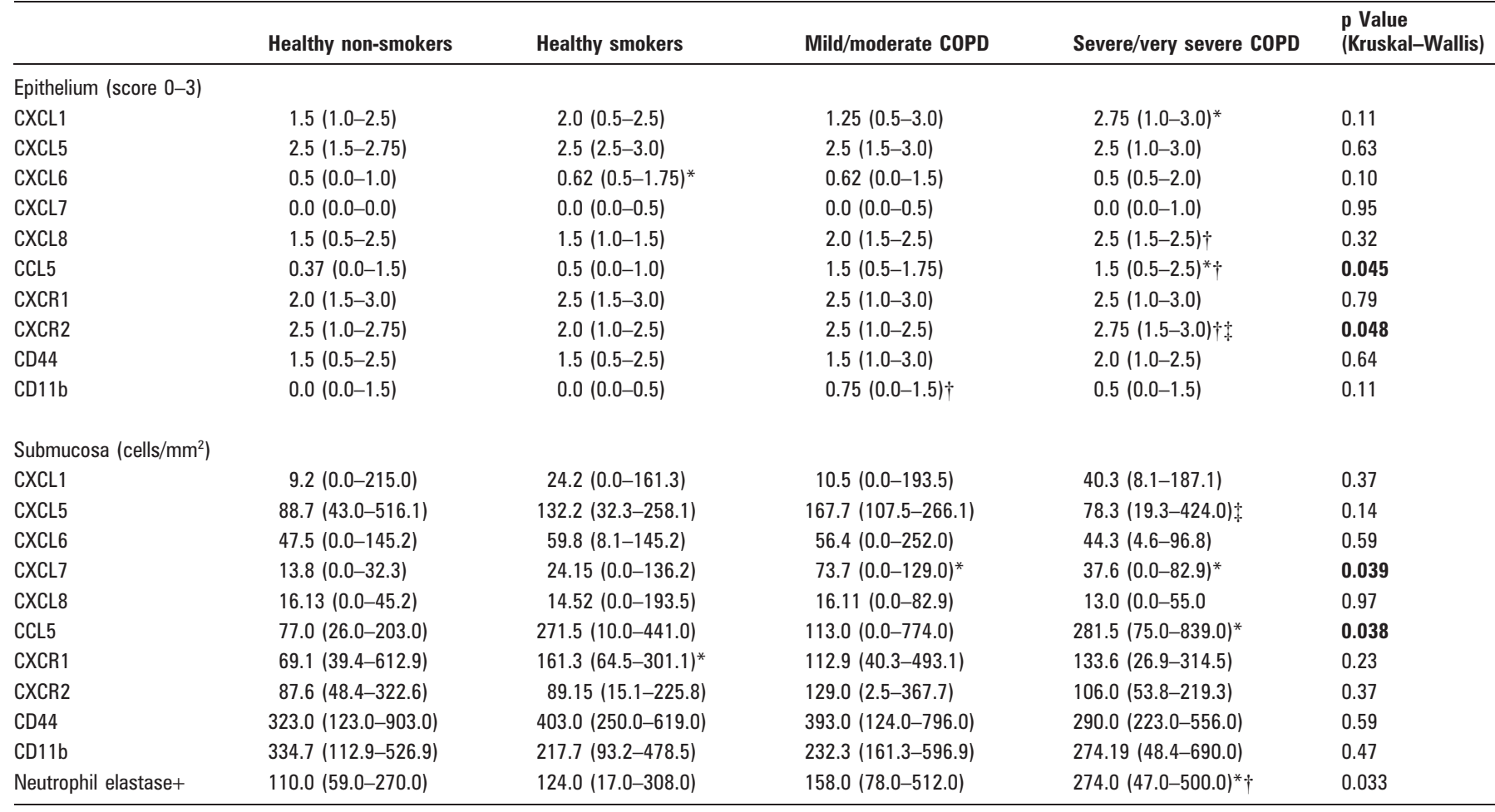

Results expressed as median (range).

COPD, chronic obstructive pulmonary disease; GOLD, global obstructive lung disease initiative (www.goldcopd.com).

The Kruskal-Wallis test was applied for multiple comparisons. For comparison between groups the Mann-Whitney U test was applied. The exact $\mathrm{p}$ values for comparison between groups are given in the Results section.

${ }^{*} \mathrm{p}<0.05$ significantly different from control non-smokers. $\uparrow \mathrm{p}<0.05$ significantly different from control smokers with normal lung function (healthy smokers). $\mathrm{t} p<0.05$ significantly different from mild/moderate COPD.

Immunohistochemistry was performed on cryostat sections of one bronchial biopsy from each of the patients with COPD and control healthy subjects.

the "co-localisation coefficients"32 (see online data supplement for details).

\section{Quantification of chemokine and cytokine mRNA levels in bronchial biopsies}

Total RNA was extracted (Micro RNeasy Kit, Qiagen, Milan, Italy) from $30 \mu \mathrm{m}$ thick cryostat sections of bronchial biopsies and $1 \mu \mathrm{g}$ used for cDNA synthesis. Relative levels of mRNAs were expressed as the ratio of the $\mathrm{Ct}$ value for the gene of interest $\mathrm{Ct} /$ housekeeping gene $\mathrm{Ct}$ (see online data supplement for details).

\section{Western blot analysis for CCL5, CXCL7 and CXCL8 in bronchial biopsies}

Whole cell protein extraction from bronchial biopsies, gel electrophoresis, nitrocellulose filters transfer, incubation with appropriate primary antibodies, detection on nitrocellulose filters and protein quantification were performed as previously described $^{6}$ (see online data supplement for details).

\section{Data analysis}

Group data were expressed as mean (SEM) for functional data or median (range) for morphological data. Differences between groups were analysed using analysis of variance (ANOVA or Kruskal-Wallis as appropriate) for functional data or nonparametric tests for morphological parameters (see online data supplement for details).

\section{RESULTS}

\section{Clinical findings}

The characteristics of subjects used for immunohistochemistry are shown in table 1. Tables E1-E3 (see online data supplement) show the characteristics of subjects used for confocal immunofluorescence, RT-QPCR and Western blotting, respectively. The four groups of subjects were of similar age (table 1). Smoking history was similar in patients with mild/moderate COPD, severe COPD and healthy smokers with normal lung function. As expected from the selection criteria, the values of forced expiratory volume in $1 \mathrm{~s}$ ( $\mathrm{FEV}_{1} \%$ predicted) and $\mathrm{FEV}_{1} /$ forced vital capacity (FVC) (\%) were significantly different in the groups with mild/moderate and severe/very severe COPD compared with both control groups (healthy smokers and healthy never-smokers). Patients with severe/very severe COPD also differed significantly from those with mild/moderate COPD (for overall groups, $\mathrm{p}<0.001$ (ANOVA) for $\mathrm{FEV}_{1} \%$ predicted and $\mathrm{FEV}_{1} / \mathrm{FVC} \%$ values).

\section{Immunohistochemistry}

\section{Neutrophils in bronchial submucosa}

The number of neutrophils, as previously reported, ${ }^{6}$ was significantly higher in the bronchial submucosa of patients with severe/very severe COPD (274 (range 47-500)) compared with control healthy smokers (124 (17-308), $p=0.008)$ and healthy never smokers (110 (59-270), $p=0.009$; table 3). Patients with mild/moderate COPD did not differ significantly from both control groups, nor did the two control groups differ significantly from each other. 

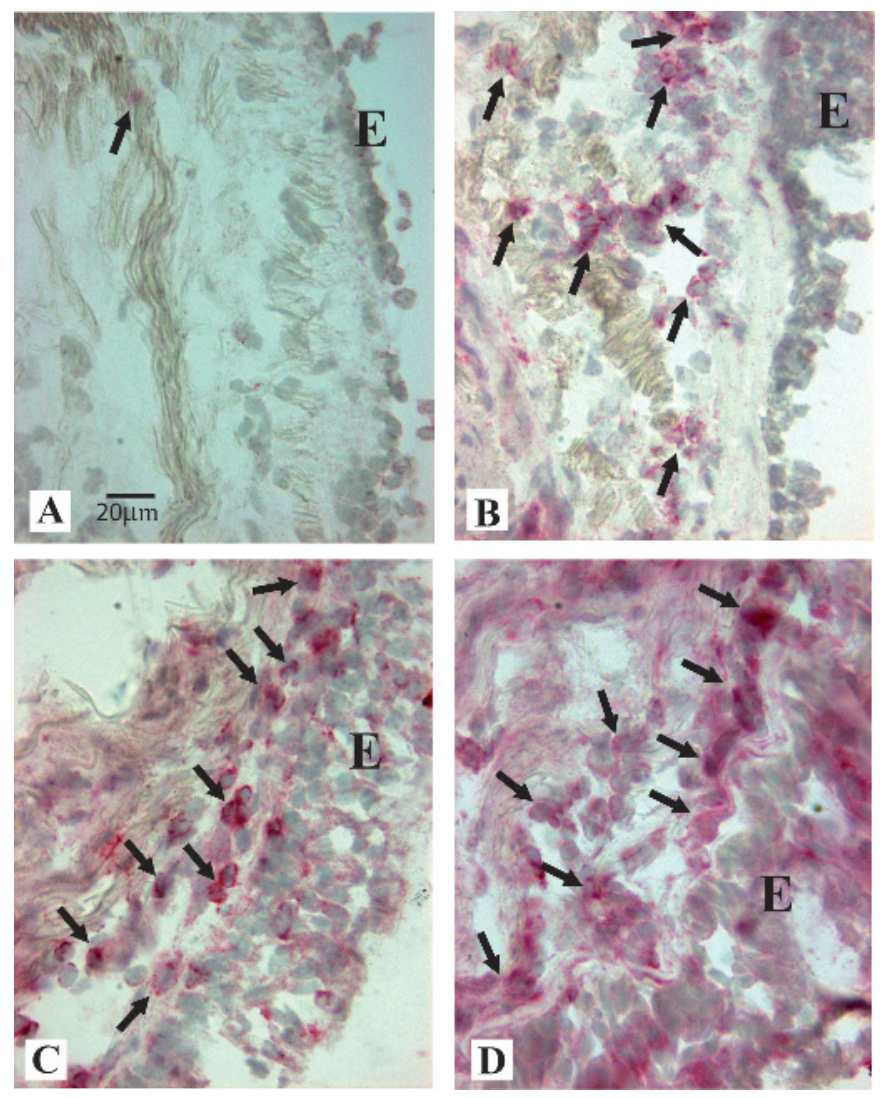

Figure 1 Photomicrographs showing the bronchial mucosa from $(A)$ a control non-smoker, $(B)$ a healthy smoker with normal lung function, (C) a patient with mild/moderate stable chronic obstructive pulmonary disease (COPD) and (D) a patient with severe stable COPD immunostained for identification of CCL5+ cells (arrows) in the submucosa. The results are representative of those from 11 nonsmokers, 13 healthy smokers, 12 patients with mild/moderate COPD and 13 with severe COPD. $E=$ epithelium. Bar $=20 \mu \mathrm{m}$.

Neutrophilic chemokines and their receptors Immunohistochemical expression of neutrophilic chemokines and their receptors in bronchial epithelium

CXCL1 expression was significantly increased in the bronchial epithelium in patients with severe/very severe COPD compared with control healthy never-smokers ( $p=0.040$, Mann-Whitney U test). Similarly, CXCL8 expression was significantly increased in the bronchial epithelium of patients with severe/very severe COPD compared with control healthy smokers $(p=0.022$, Mann-Whitney U test). CCL5 showed significantly enhanced expression in the bronchial epithelium of patients with severe/ very severe COPD compared with control healthy smokers $(p=0.042)$ and healthy never smokers $(p=0.048$, MannWhitney U test). Finally, CXCR2 was significantly increased in patients with severe/very severe COPD compared with patients with mild/moderate COPD $(p=0.043)$ and control healthy smokers ( $p=0.018$, Mann-Whitney U test; table 3$)$. No significant differences were observed between the four groups of subjects for all the other proteins investigated in the bronchial epithelium.

Immunohistochemical expression of neutrophilic chemokines and their receptors in bronchial submucosa

CCL5 immunostaining was the one most abundantly observed in this study and was present in inflammatory and structural
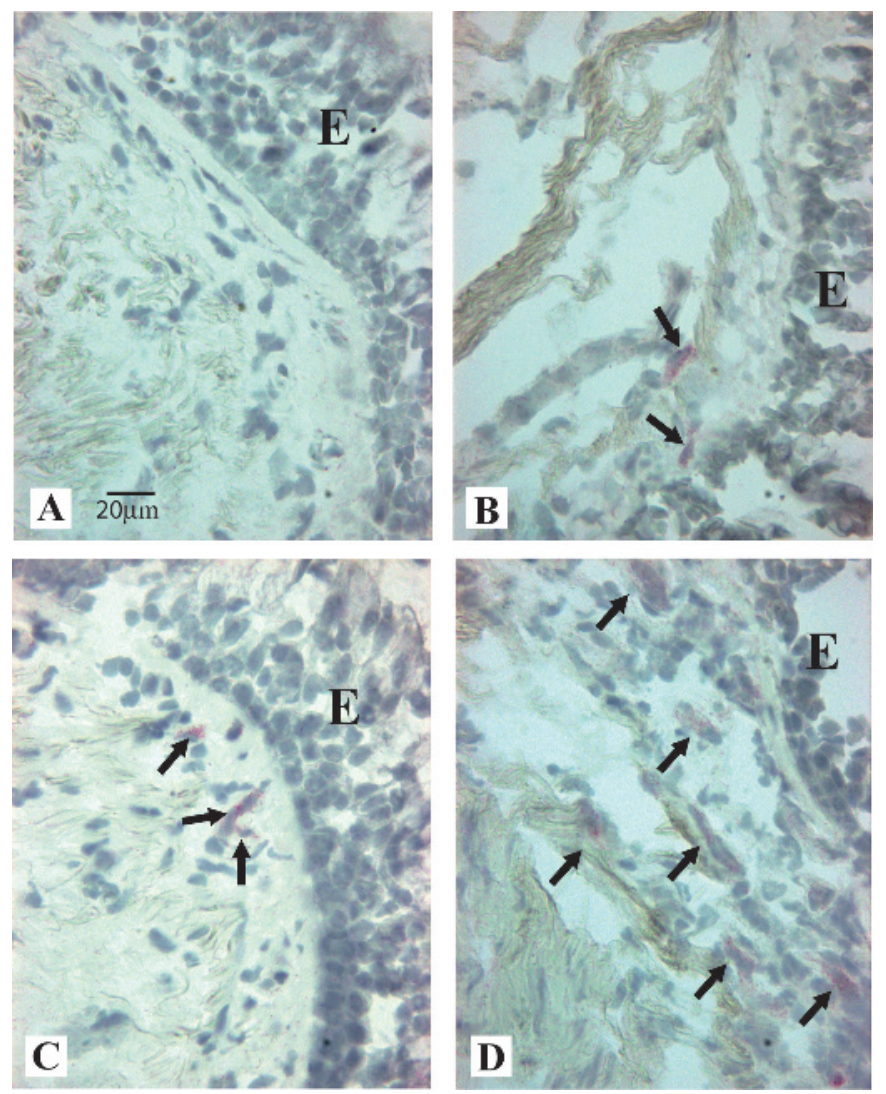

Figure 2 Photomicrographs showing the bronchial mucosa from $(A)$ a control non-smoker, (B) a healthy smoker, (C) a patient with mild/ moderate stable chronic obstructive pulmonary disease (COPD) and (D) a patient with severe stable COPD immunostained for identification of CXCL7+ cells (arrows) in the submucosa. The results are representative of those from 11 non-smokers, 13 healthy smokers, 12 patients with mild/moderate COPD and 13 with severe COPD. $E=$ epithelium. Bar $=20 \mu \mathrm{m}$.

cells-mainly in endothelial cells and occasionally in the smooth muscle - within the bronchial submucosa (fig 1). The number of CCL5+ cells was significantly higher in patients with severe/ very severe COPD (281 (range 75-839)) than in control healthy never-smokers (77 (range 26-203), $\mathrm{p}=0.002$ ), but it did not differ from control smokers or patients with mild/moderate COPD (table 3).

Immunostaining for CXCL7 was observed in inflammatory cells, endothelial cells, fibroblasts and submucosal glands in the bronchial submucosa (fig 2), but its expression was 2-7 times lower than that for CCL5. The number of CXCL7+ cells was significantly higher in patients with severe/very severe COPD (37.6 (range $0-82.9), p=0.004)$ than in control healthy neversmokers (13.8 (0-32.3), table 3).

In contrast, immunostaining for CXCL1 and CXCL6 was observed in relatively few inflammatory cells and endothelial cells in the bronchial submucosa, and the numbers of CXCL1+ and CXCL6+ cells did not differ between the four groups studied. The number of CXCL1+ cells in the bronchial submucosa was 7-10 times lower than CCL5 and the number of CXCL6+ cells was 2-7 times lower than CCL5 (table 3).

CXCL5 immunostaining was localised in inflammatory and endothelial cells in the bronchial submucosa. The numbers of CXCL5+ cells was significantly lower in patients with severe/ 


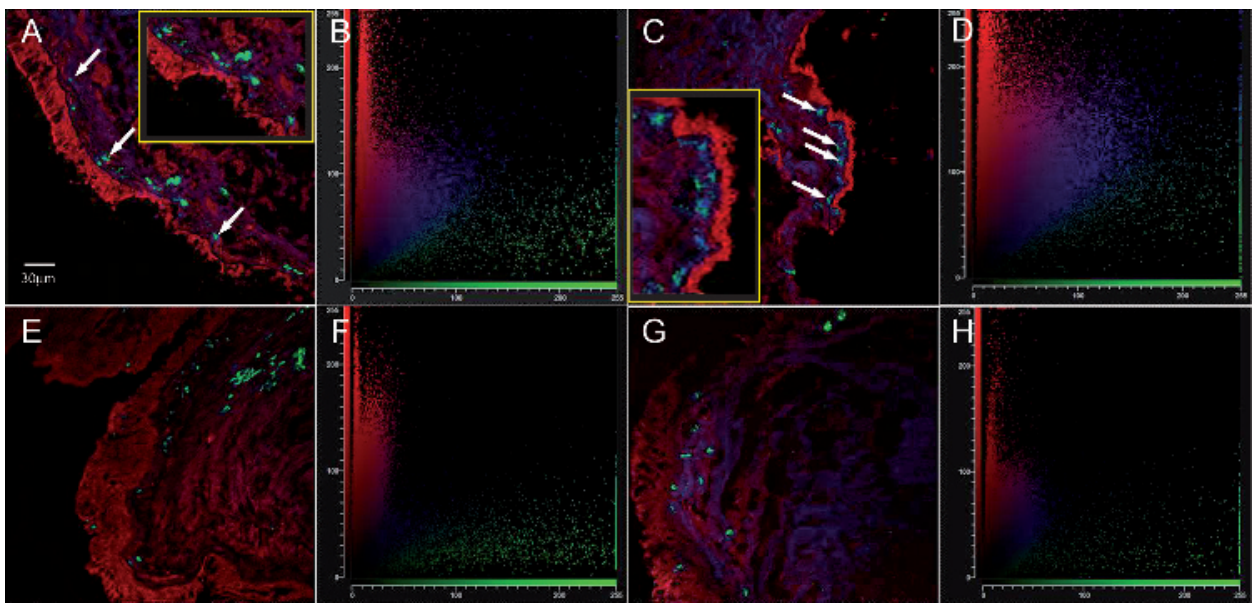

Figure 3 Representative double-labelled confocal fluorescence images showing double staining for neutrophil elastase and CD44 or CD11b in the bronchial mucosa from four patients with stable chronic obstructive pulmonary disease (COPD) (A-D) and four healthy smokers (E-H). Cryostat sections were fixed with paraformaldehyde and incubated with the primary and secondary antibodies. Images $A$ and $C$ were obtained from one patient with severe COPD. Images E and G were obtained from a control healthy smoker. Images A and E show the co-expression levels of neutrophil elastase (Alexa Fluor 488-green) and CD44 (Alexa Fluor 647-red), whereas images C and G represent the co-expression levels of neutrophil elastase (Alexa Fluor 488-green) and CD11b (Alexa Fluor 647-red). Co-localised pixels are shown in blue (arrows). Panels B, D, F and $\mathrm{H}$ show the correlation cytofluorogram of the images in $A, B, C$ and $E$, respectively. Inserts show double-stained cells at higher magnification.

very severe COPD (78.3 (range 19-424), $\mathrm{p}=0.025)$ than in those with mild/moderate COPD (167.7 (107-266), table 3).

CXCL8 immunostaining was observed in few inflammatory cells and occasionally in capillary vessels (endothelial cells) and smooth muscle cells in the bronchial submucosa, its expression being 5-15 times lower than that of CCL5. No significant differences were observed in the numbers of CXCL8+ cells between any of the groups studied (table 3).

Immunostaining for CXCR1 was observed in inflammatory cells, endothelial cells and, to a lesser extent, in fibroblasts within the bronchial submucosa. The number of CXCR1+ cells in the bronchial submucosa of control healthy smokers (161.3 (range 64-301), $p=0.038$ ) was significantly higher than in control healthy never-smokers (69.1 (39.4-612.9)) but not than the other groups. Similar to CXCR1, immunostaining for CXCR2 was observed in inflammatory cells, endothelial cells and, to a lesser extent, in fibroblasts. No significant differences were observed in the numbers of CXCR2+ cells counted in the bronchial submucosa of the four groups studied (table 3).

CD11b staining was observed in inflammatory cells, endothelial cells, fibroblasts and occasionally in the smooth muscle with no significant differences being observed between any of the groups studied. CD44 staining was also observed in inflammatory cells, fibroblasts, endothelial cells and occasionally in the smooth muscle, and again no significant differences were observed in the numbers of CD44+ cells counted in the bronchial submucosa between any of the groups (table 3 ).

\section{Immunofluorescence with confocal microscopy double staining for identification of neutrophil granulocytes co-expressing CD11b or CD44}

Confocal microscopy showed that the percentage of neutrophils co-expressing CD11b in the bronchial submucosa was significantly higher in patients with severe/very severe COPD than in control healthy smokers (mean (SD) 46 (5)\% vs 16 (4)\%, $p=0.02$ ). Similarly, the percentage of neutrophils co-expressing CD44 was significantly increased in patients with severe/very severe COPD compared with control healthy smokers (mean (SD) $48(6) \%$ vs 14 (4\%), $p=0.02$; fig 3 ).

Quantification of neutrophilic chemokine mRNA levels

The mRNA levels expressed as $45-\Delta \mathrm{Ct}$ and relative levels of mRNAs expressed as the ratio of the gene of interest $\mathrm{Ct} /$ housekeeping $\mathrm{Ct}$ (guanine nucleotide binding protein ( $\mathrm{G}$ protein) - GNB2L) are shown in table 4. Whether measured as relative or absolute levels, the expression of CXCL7 and CCL5 mRNA was significantly higher in biopsy specimens from patients with COPD than in those from control healthy smokers with normal lung function. In contrast, there was no significant difference in the expression of CXCL8 mRNA between these two groups.

\section{Western blot analysis for CCL5, CXCL7 and CXCL8}

From Western blot analysis, no significant difference was seen in the expression of CCL5 in bronchial biopsies from patients with COPD compared with healthy smokers with normal lung function (CCL5/actin ratio 0.84 (0.07) vs $0.63(0.09), p=0.06$, fig 4). CXCL7 (data not shown) and CXCL8 expression (fig 4) were both below the detection threshold in the bronchial mucosa of patients with COPD and control healthy smokers with normal lung function.

Correlations between inflammatory cell counts, neutrophilic chemokines and their receptors and clinical parameters

In all smokers the number of neutrophils in the bronchial submucosa correlated positively and significantly with CD44 epithelial expression $(r=0.47, p=0.046)$. No other statistically significant correlations were found between inflammatory cells and neutrophilic chemokine expression or any clinical parameters.

\section{DISCUSSION}

This study demonstrates for the first time the presence of an increased number of CCL5+ and CXCL7+ cells and an increased 
expression of both CCL5 and CXCL7 mRNA in the bronchial mucosa of patients with severe/very severe COPD in the stable phase as well as an increased number of neutrophils in the bronchial submucosa. We also found a significant upregulation of $\mathrm{CD} 44$ and $\mathrm{CD} 11 \mathrm{~b}$ receptors on neutrophils within the bronchial submucosa of patients with COPD compared with control healthy smokers.

CCL5 was the most abundant chemokine expressed in the bronchial mucosa of patients with severe COPD, showing levels of immunostained cells 2-15 times higher than those of other chemokines. The increased expression of both CCL5 and CXCL7 mRNA in the patients with COPD compared with control healthy smokers indicates that the expression of these chemokines is regulated at the transcriptional level and/or by increased mRNA stabilisation. Looking at the total protein expression by Western blot analysis, we found a trend towards increased CCL5 expression in the bronchial mucosa of patients with COPD compared with control healthy smokers, in agreement with RT-OPCR analysis. These findings are apparently in contrast to our quantification of CCL5+ cells by immunohistochemistry in the submucosa which showed a statistically significant difference only when patients with severe/very severe COPD were compared with control healthy never smokers. This may be due to the fact that quantification of the total amount of mRNA or protein by RT-OPCR or Western blotting, respectively, represents the sum of epithelial and submucosal mRNA expression or the sum of intracellular and extracellular proteins in the bronchial mucosa, not necessarily corresponding to the direct quantification of the number of cells expressing the same molecule as performed by immunohistochemistry in a single compartment (ie, the submucosa). CCL5 binding to glycosaminoglycans on the cell surface or in the extracellular matrix sequesters CCL5, thereby immobilising CCL5 to provide a directional signal. ${ }^{33}$ This may explain why increased levels of CCL5 have been reported in the BAL fluid of patients with COPD with a bronchodilator response compared with non-smoking subjects, ${ }^{34}$ and why lipopolysaccharide-stimulated COPD cultured lung explants release more CCL5 than control healthy smokers. ${ }^{25}$ In fact, part of this extracellular chemokine can be released after stimulation or recovered in the BAL fluid. Furthermore, the lack of a significant positive correlation between numbers of neutrophils

Table 4 Results of the RT-QPCR study

\begin{tabular}{llll}
\hline & $\begin{array}{l}\text { Healthy smokers } \\
(\mathbf{n}=7)\end{array}$ & $\begin{array}{l}\text { COPD patients } \\
(\mathbf{n}=24)\end{array}$ & $\begin{array}{l}\text { p Value } \\
\text { (Mann- } \\
\text { Whitney test) }\end{array}$ \\
\hline $\begin{array}{l}\text { Absolute mRNA levels } \\
\text { CCL5 }\end{array}$ & $19.77(1.2)$ & $24.32(2.6)$ & $<0.001$ \\
CXCL7 & $16.95(1.9)$ & $21.77(1.8)$ & 0.001 \\
$\quad$ CXCL8 & $18.27(1.5)$ & $19.07(1.6)$ & 0.88 \\
$\begin{array}{l}\text { Relative mRNA levels } \\
\text { CCL5 }\end{array}$ & $0.95(0.1)$ & $1.34(0.2)$ & $<0.001$ \\
CXCL7 & $0.79(0.01)$ & $0.96(0.14)$ & 0.001 \\
CXCL8 & $0.88(0.06)$ & $0.91(0.08)$ & 0.94 \\
\hline
\end{tabular}

Data are shown as mean (SEM).

The non-parametric Mann-Whitney $\mathrm{U}$ test was used for comparisons between patients with chronic obstructive pulmonary disease (COPD) and healthy smokers.

mRNA extraction and RT-QPCR analysis was performed using one cryostat section ( $30 \mu \mathrm{m}$ thick) of one bronchial biopsy from each of the patients with COPD and control healthy smokers studied. For absolute levels, expressed as $45-\Delta \mathrm{Ct}$, higher values indicate higher mRNA levels. Relative levels of mRNAs expressed as the ratio of the gene of interest $\mathrm{Ct} /$ housekeeping $\mathrm{Ct}$ (guanine nucleotide binding protein (G protein) GNB2L). and numbers of CCL5+ cells populating the bronchial mucosa, observed in the present study, may also be partly due to this intracellular and extracellular CCL5 protein distribution pattern. In addition, our finding that increased neutrophilia in the bronchial mucosa is dependent on different mechanisms such as the increased presence of chemotactic stimuli and increased neutrophil adhesiveness suggests that a direct correlation between numbers of neutrophils and every chemotactic factor could not be found, as we observed. These data also suggest that studies on the expression of neutrophilic chemokines obtained in different compartments such as blood, sputum and BAL fluid may not be fully representative of the inflammatory cascade recruiting cells in the lower airways of patients with COPD. In addition, the low levels of CXCL7 and CXCL8 expression seen by immunohistochemistry were reflected in the inability to detect these proteins by Western blotting, which requires a much higher level of protein expression than immunohistochemistry.

The chemokine receptors CXCR1 and CXCR2 were not significantly different in the four groups of subjects studied except for a significantly increased expression of CXCR2 in the epithelium of patients with severe COPD compared with control healthy smokers and patients with mild/moderate COPD. This suggests that there may be enhanced activation of CXCR2 in stable severe disease, possibly interacting with the increased CXCL7 ligand and both contributing, in part, to increased neutrophilia in patients with severe/very severe COPD. We believe, however, that the lack of a significant increase in CXCR1, CXCR2 and related CXC chemokines in the bronchial submucosa of our patients indicates that these receptors/chemokines do not have a major role during stable COPD, but they may have a more prominent role during COPD exacerbations as the expression of CXCL5, CXCL8, CXCR1 and CXCR2 has been reported to be increased in bronchial biopsies of patients with COPD with severe exacerbations. ${ }^{15}$

Functionally, CCL5 is a member of a family of CC chemokines that includes other members such as CCL2, CCL3 and CCL4 with strong chemoattractant activity towards

a

\section{CCL5}
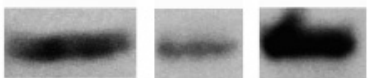

Actin

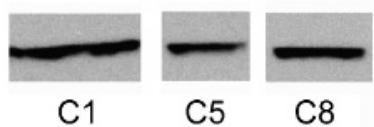

b

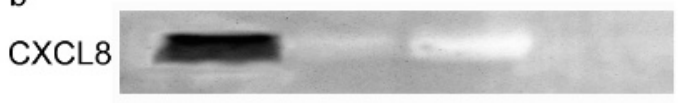

Actin

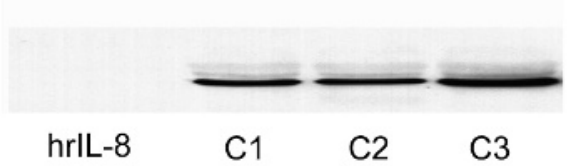

Figure 4 Representative Western blot analysis of (a) CCL5 and (b) CXCL8 expression in bronchial biopsies of three patients with stable chronic obstructive pulmonary disease (COPD). Total cellular proteins were size-fractionated by SDS-PAGE and CCL5 and CXCL8 were detected using specific antibodies. The positive control lane in (b) has been loaded with human recombinant (hr) CXCL8. Western blotting was performed on five smokers with normal lung function and seven patients with COPD. 
monocytes and natural killer (NK) cells. We previously reported increased levels of CCL2 and CCL4 in the BAL fluid of patients with stable COPD compared with control smokers, ${ }^{35}$ and an upregulation of CCL3 in the bronchial epithelium and an increased number of NK+ cells in the bronchial submucosa of patients with severe/very severe COPD compared with control healthy smokers. ${ }^{5}$ Together these findings suggest that, in patients with stable COPD, CC chemokines may play a predominant role in sustaining tissue neutrophilia and infiltration of macrophages and NK cells. In contrast, CXC chemokines and their receptors predominate during COPD exacerbations. ${ }^{11}{ }^{15}$ The fact that CXCL1, CXCL5 and CXCL6 were not changed in the submucosa of patients with COPD in comparison with both control groups in the present study further confirms our view of a major role for CC chemokines in the bronchial tissue of patients with stable COPD. CCL5 is also chemotactic for eosinophils, but an increased number of eosinophils in the bronchial mucosa has only been demonstrated during COPD exacerbations ${ }^{15}$ and not in stable disease. ${ }^{4}$ For this reason we did not quantify the number of eosinophils in the bronchial mucosa of patients with stable COPD.

Interestingly, we report here for the first time that expression of the receptors CD11b and CD44 in the neutrophils is 3-4 times higher in the bronchial submucosa of patients with COPD than in control healthy smokers, suggesting a greater activation state and higher adhesive capability of these cells to bind to submucosal extracellular matrix components. This further supports a role for these receptors in anchoring neutrophils to some components of the extracellular matrix such as hyaluronic acid molecules and adhesion molecules such as intercellular adhesion molecule 1 (ICAM-1) and endothelial-leucocyte adhesion molecule 1 (ELAM-1). ELAM-1 is highly expressed in bronchial capillary vessels whereas ICAM-1 is preferentially expressed in the epithelium of the bronchial mucosa. ${ }^{29}$ These data, obtained from segmental and subsegmental bronchi, need to be evaluated in the smaller bronchi and bronchioles of patients with COPD.

Differences in the environment between tissue and sputum may account for the differences in the activation status of neutrophils seen in the bronchial mucosa and those isolated from sputum which show a hypofunctional state and chemotactic response. ${ }^{10}$ The fact that sputum neutrophils are usually in a terminal stage of life may also contribute to these differences and further underlines the importance of data obtained from analysis of the bronchial tissue of patients with COPD.

In conclusion, the prominent expression of the chemokine CCL5 and, to a lesser extent, of CXCL7 together with higher neutrophil adhesiveness may account for the increased neutrophilia observed in the bronchial mucosa of patients with severe COPD. Identification of the individual contribution of each of these chemokines in inducing neutrophilia in patients with severe/very severe COPD will require clinical trials using selective antagonists or blocking antibodies to each of these molecules, many of which are already in development.

Funding: This work was supported by Fondazione Salvatore Maugeri, IRCCS, Ricerca Corrente and Regione Piemonte, Ricerca Sanitaria Finalizzata. IMA and PJB are supported by the Wellcome Trust.

\section{Competing interests: None.}

Ethics approval: The study conformed to the Declaration of Helsinki. Ethics consent was obtained, bronchial biopsies were performed according to the local ethics committee guidelines and informed consent was obtained from each subject.

Provenance and peer review: Not commissioned; externally peer reviewed.

\section{REFERENCES}

1. Global Initiative for Chronic Obstructive Lung Disease. Global strategy for the diagnosis, management and prevention of chronic obstructive pulmonary disease. NIH Publication No 2701:1-100. NHLBI/WHO Workshop Report. Bethesda: National Heart, Lung and Blood Institute, April 2001 (last update 2008). http://www.goldcopd. com (accessed 24 Apr 2008).

2. Barnes PJ. Chronic obstructive pulmonary disease. N Engl J Med 2000;343:269-80

3. Hogg JC, Chu F, Utokaparch S, et al. The nature of small-airway obstruction in chronic obstructive pulmonary disease. N Engl J Med 2004;350:2645-53.

4. Di Stefano A, Caramori G, Ricciardolo FLM, et al. Cellular and molecular mechanisms in chronic obstructive pulmonary disease: an overview. Clin Exp Allergy 2004;34:1156-67.

5. Di Stefano A, Capelli A, Lusuardi M, et al. Severity of airflow limitation is associated with severity of airway inflammation in smokers. Am J Respir Crit Care Med 1998:158:1277-85.

6. Ricciardolo FLM, Caramori G, Ito K, et al. Nitrosative stress in the bronchial mucosa of severe chronic obstructive pulmonary disease. J Allergy Clin Immunol 2005; 116:1028-35.

7. Hodge SJ, Hodge GL, Holmes M, et al. Flow cytometric characterization of cell populations in bronchoalveolar lavage and bronchial brushings from patients with chronic obstructive pulmonary disease. Cytometry B Clin Cytom 2004;61:27-34.

8. Thompson AB, Daughton D, Robbins RA, et al. Intraluminal airway inflammation in chronic bronchitis. Characterization and correlation with clinical parameters. Am Rev Respir Dis 1989;140:1527-37.

9. Fujimoto K, Yasuo M, Urushibata K, et al. Airway inflammation during stable and acutely exacerbated chronic obstructive pulmonary disease. Eur Respir $\mathrm{J}$ 2005;25:640-6.

10. Yoshikawa T, Dent G, Ward J, et al. Impaired neutrophil chemotaxis in chronic obstructive pulmonary disease. Am J Respir Crit Care Med 2007;175:473-9.

11. Viola A, Luster $A D$. Chemokines and their receptors: drug targets in immunity and inflammation. Annu Rev Pharmacol Toxicol 2008;48:171-97.

12. Traves SL, Culpitt S, Russell REK, et al. Elevated levels of the chemokines GRO- $\alpha$ and MCP-1 in sputum samples from COPD patients. Thorax 2002;57:590-5.

13. Imaizumi T, Albertine $\mathrm{KH}$, Jicha DL, et al. Human endothelial cells synthesize ENA78: relationship to IL-8 and to signaling of PMN adhesion. Am J Respir Cell Mol Biol 1997:17:181-92.

14. Tanino M, Betsuyaku T, Takeyabu K, et al. Increased levels of interleukin-8 in BAL fluid from smokers susceptible to pulmonary emphysema. Thorax 2002;57:405-11.

15. Oiu Y, Zhu J, Bandi V, et al. Biopsy neutrophilia, chemokine and receptor gene expression in severe exacerbations of COPD. Am J Respir Crit Care Med 2003:168:968-75

16. Van Damme J, Wuyts A, Froyen G, et al. Granulocyte chemotactic protein-2 and related CXC chemokines: from gene regulation to receptor usage. J Leukoc Biol 1997;62:563-9.

17. Wuyts A, Struyf S, Gijsbers K, et al. The CXC chemokine GCP-2/CXCL6 is predominantly induced in mesenchymal cells by interleukin-1beta and is downregulated by interferon-gamma: comparison with interleukin-8/CXCL8. Lab Invest 2003:83:23-34.

18. Walz A. Generation and properties of neutrophil-activating peptide 2. Cytokines 1992:4:77-95.

19. Traves SL, Smith SJ, Barnes PJ, et al. Specific CXC but not CC chemokines cause elevated monocyte migration in COPD: a role for CXCR2. J Leukoc Biol 2004;76:441-50.

20. Rossi D, Zlotnik A. The biology of chemokines and their receptors. Annu Rev Immunol 2000; 18:217-42

21. Yamamoto C, Yoneda T, Yoshikawa M, et al. Airway inflammation in COPD assessed by sputum levels of interleukin-8. Chest 1997;112:505-10.

22. Gompertz S, O'Brien C, Bayley DL, et al. Changes in bronchial inflammation during acute exacerbations of chronic bronchitis. Eur Respir J 2001;17:1112-9.

23. Costa C, Rufino R, Traves SL, et al. CXCR3 and CCR5 chemokines in induced sputum from patients with COPD. Chest 2008;133:26-33

24. Fujimoto $\mathbf{K}$, Yasuo M, Urushibata $\mathrm{K}$, et al. Airway inflammation during stable and acutely exacerbated chronic obstructive pulmonary disease. Eur Respir $J$ 2005;25:640-6.

25. Smyth LJC, Starkey C, Gordon FS, et al. CD8 chemokine receptors in chronic obstructive pulmonary disease. Clin Exp Immunol 2008:154:56-63.

26. Noquera A, Busquets $X$, Sauleda J, et al. Expression of adhesion molecules and G proteins in circulating neutrophils in chronic obstructive pulmonary disease. Am J Respir Crit Care Med 1998:158:1664-8.

27. Yamagata T, Sugiura H, Yokoyama T, et al. Overexpression of CD11b and CXCR1 on circulating neutrophils. Its possible role in COPD. Chest 2007:132:890-9.

28. Pignatti $\mathbf{P}$, Moscato G, Casarini S, et al. Downmodulation of CXCL8/LL-8 receptors on neutrophils after recruitment in the airways. J Allergy Clin Immunol 2005;115:88-94.

29. Di Stefano A, Maestrelli P, Roggeri A, et al. Upregulation of adhesion molecules in the bronchial mucosa of subjects with obstructive chronic bronchitis. Am J Respir Crit Care Med 1994;149:803-10.

30. Yasuda M, Nakano K, Yasumoto K, et al. CD44: functional relevance to inflammation and malignancy. Histol Histopathol 2002:17:945-50.

31. Yousefi S, Cooper PR, Mueck B, et al. cDNA representational difference analysis of human neutrophils stimulated by GM-CSF. Biochem Biophys Res Commun 2000;277:401-9. 
32. Manders EMMM, Verbeek FJ, Aten JA. Measurement of co-localization of objects in dual-colour confocal images. J Microscopy 1993;169:375-438.

33. Murooka TT, Wong MM, Rahbar R, et al. CCL5-CCR5-mediated apoptosis in T cells: requirement for glycosaminoglycan binding and CCL5 aggregation. J Biol Chem 2006;281:25184-94.
34. Miller M, Ramsdell J, Friedman PJ, et al. Computed tomographic scan-diagnosed chronic obstructive pulmonary disease-emphysema: eotaxin-1 is associated with bronchodilator response and extent of emphysema. J Allergy Clin Immunol 2007;120:1118-25.

35. Capelli A, Di Stefano A, Gnemmi I, et al. Increased MCP-1 and MIP-1 $\beta$ in bronchoalveolar lavage fluid of chronic bronchitics. Eur Respir J 1999;14:160-5.

\section{Lung alert}

\section{Epinephrine and dexamethasone reduce hospital admission in children with bronchiolitis}

Bronchiolitis is the most common acute infection of the lower respiratory tract in infants. This multicentre, randomised, double-blind, placebo controlled clinical trial was conducted in response to controversy surrounding the current treatment of bronchiolitis.

Patients were recruited at eight Canadian paediatric emergency departments from 2004 through 2007. Bronchiolitis was defined as the first episode of wheezing associated with signs of an upper respiratory tract infection during the peak respiratory syncytial virus season. A total of 3556 infants (aged 6 weeks to 12 months) were assessed for eligibility; 2756 were excluded and 800 were enrolled and randomised into four groups: nebulised epinephrine plus oral dexamethasone (group 1); nebulised epinephrine plus oral placebo (group 2); nebulised placebo plus oral dexamethasone (group 3); and nebulised placebo plus oral placebo (group 4).

Combining epinephrine and dexamethasone led to a reduction in the rate of hospital admissions within 7 days (primary outcome). There was a relative risk reduction of $35 \%$ compared with placebo. Infants in group 1 had lower respiratory rates and lower respiratory distress assessment index scores during the first hour of the study, were discharged earlier from medical care and appeared to return to quiet breathing and normal or almost normal feeding more quickly (secondary outcomes) than those in the placebo group. Dexamethasone and epinephrine alone did not affect these outcomes.

Controversy still exists in the management of bronchiolitis, but this study suggests that the combination of dexamethasone and epinephrine is beneficial and a starting point for further research.

- Plint AC, Johnson DW, Patel H, et al, for Pediatric Emergency Research Canada (PERC). Epinephrine and dexamethasone in children with bronchiolitis. N Engl J Med 2009;360:2079-89.

\section{P Terezinha Fiandeiro}

Correspondence to: Dr P Terezinha Fiandeiro, ST1 CMT, North Middlesex Hospital, London, UK; pfiandeiro@yahoo.com

Provenance and peer review: Not commissioned; not externally peer reviewed.

Thorax 2009;64:975. doi:10.1136/thx.2009.123273 